\title{
Análise das classificações supervisionada e não supervisionada com o uso de imagens Landsat 5 TM e RapidEye, e suas contribuições para o mapeamento do uso e cobertura do solo no Parque Nacional das Emas
}

\author{
Analysis of supervised and unsupervised classifications using Landsat 5 TM and RapidEye, and your contributions to \\ the use mapping and soil cover at the Emas National Park.
}

\author{
Daniel de Oliveira Soares ${ }^{1}$ \\ Anna Claudia dos Santos ${ }^{1}$ \\ Elaine Barbosa da Silva ${ }^{1}$ \\ ${ }^{1}$ Universidade Federal de Goiás - UFG \\ Laboratório de Processamento de Imagens e Geoprocessamento - LAPIG \\ Campus II, Cx. Postal 131, CEP 74001-970, Goiânia - GO, Brasil. \\ ddosoares@gmail.com, anna.santos.ufrn@gmail.com, elainesilvaufg@gmail.com \\ Recebido em 26/01/2016 - Aceito em 08/06/2016 \\ Received on 26/01/2016 - Accepted on 08/06/2016
}

\begin{abstract}
RESUMO - Os mapeamentos de mudança da cobertura e uso do solo com o uso de sensoriamento remoto têm sido cada vez mais utilizados para os estudos ambientais. Ao longo das últimas décadas, o bioma Cerrado tem passado por diversas mudanças e transformações, e a agropecuária tem tido um papel fundamental para essa mudança. Este artigo apresenta um estudo caracterizado no Parque Nacional das Emas, localizado no extremo sudoeste do Estado de Goiás e o buffer de $10 \mathrm{~km}$ ao redor. O método utilizado foi de segmentação de imagens e classificação supervisionada e não supervisionada com o uso de satélite Landsat 5 TM, com média resolução espacial, bem como inspeção visual e validação dos dados, com o uso do satélite RapidEye, com alta resolução espacial, ambos para o ano de 2011 . O trabalho mostrou resultados satisfatórios, porque foi possível escolher qual melhor classificação se aproximaria da validação dos dados naquela área de estudo. Os mapas também resultaram com boa acurácia para estudos posteriores.

Palavras-chave: classificação supervisionada, validação, uso do solo.
\end{abstract}

ABSTRACT - Change mappings of land cover and use with the use of remote sensing has been increasingly used for environmental studies. Over the past decades, Cerrado has undergone several changes and transformations, and agriculture has played a key role in this change. This article presents a study featured in the Emas National Park, located in the extreme southwest of the state of Goias and the buffer of $10 \mathrm{~km}$ around. Method used was segmentation of images and supervised and unsupervised classifications with the use of satellite Landsat 5 TM, with an medium spatial resolution, as well as visual inspection and validation of the data, using the RapidEye satellite, with high spatial resolution, both for the year 2011. Study showed satisfactory results, because it was possible to choose which best rating would approach the validation of data in that study area. The maps also resulted with good accuracy for further studies.

Keywords: supervised classification, validation, land use.

\section{INTRODUÇÃO}

A expansão agrícola pode ser considerada um dos mais agravantes cenários para 0 aumento do desmatamento Macedo et al. (2012) e queda da biodiversidade Glatzle (2014). A intensificação dessa exploração pode causar danos ao solo, pois reduz a capacidade de infiltração aumentando as áreas com assoreamento e perda de nutrientes. A biota também é prejudicada, pois a grande fragmentação de áreas ocupadas pela agricultura impede a formação de corredores ambientais, além de acelerar o processo de evaporação da água, devido à utilização exacerbada dos pivôs centrais Bellarby et al (2008). O sudoeste goiano é uma área de agricultura consolidada e esse processo se acentuou com a ampliação da fronteira agrícola, vinda do interior paulista Franco e Assunção (2011); Silva et al (2013). A intensificação da ocupação nesta região foi beneficiada pelas suas características geomorfológicas e climáticas, possuindo um clima tropical subúmido, com duas estações bem definidas (seca e chuvosa) e um solo ótimo para o cultivo com chapadões planos, levemente ondulados que fez com que se transformassem no que atualmente é chamado de celeiro produtivo Goiano Della et al (2014).

Em meio a esta intensificação de usos, está situada uma unidade de conservação que representa um dos 
principais mosaicos de fragmentos do Cerrado, região de grande importância para conservação da biodiversidade, o Parque Nacional das Emas (PNE) França et al (2007). A retirada da vegetação circundante ao PNE, devido à grande expansão agrícola presente no Sudoeste Goiano, compromete a biota e o equilíbrio ecossistêmico do mesmo, já que impede a formação dos corredores de biodiversidade. Dessa forma, o Parque se torna uma área descontínua e, por isso, não consegue cumprir seu objetivo de elemento preservador do Cerrado Vidolin et al (2004). As áreas de ocupação agrícola, bem como as do interior do PNE, podem ser monitoradas com tecnologias eficazes e de baixo custo. Um exemplo é o uso de imagens das séries dos satélites Landsat que foram utilizadas nos mapeamentos de uso e coberturas das terras do bioma Cerrado pelo Ministério do Meio Ambiente em 2002 em âmbito do PROBIO e, recentemente no projeto TerraClass Cerrado.

A identificação detalhada dos tipos de uso da região se torna cada vez mais utilizada para diversos fins, devido à disponibilização de imagens com diferentes resoluções espectrais e radiométricas, em curtos intervalos de tempo. Além do desenvolvimento de metodologias para classificação e segmentação que conseguem dar uma resposta mais detalhada da dinâmica do uso da terra.

O presente artigo apresenta o resultado do uso comparativo de métodos de classificação, objetivando a obtenção de mapeamentos capazes de proporcionar informações detalhadas quanto ao uso do solo no Parque Nacional das Emas e com este intuito, obter subsídios de um monitoramento e análise da situação atual que se encontra a região de estudo, para tal, utilizou-se neste trabalho, os métodos de classificação supervisionada e não supervisionada, método por segmentação de imagens de sensoriamento remoto.

\section{METODOLOGIA}

O fluxograma a seguir detalha como foi elaborada a metodologia deste trabalho:

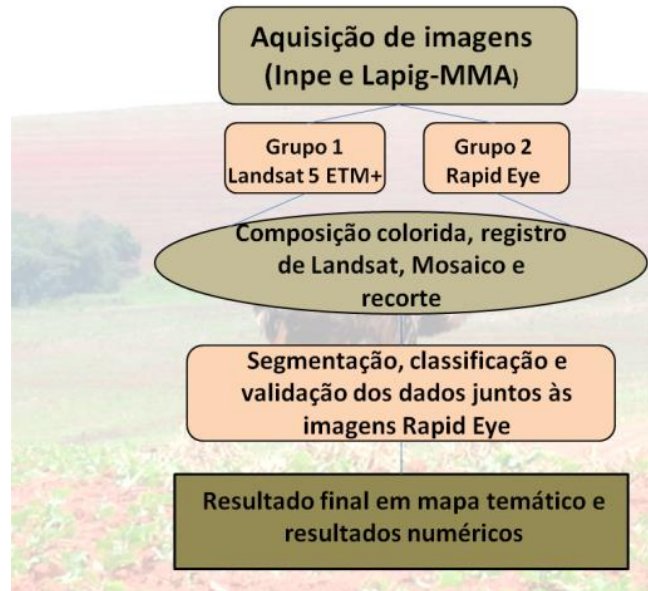

Figura 1: Fluxograma das etapas metodológicas. Fonte: Autor
O primeiro passo foi a delimitação da área. A área de estudo escolhida está localizada na Região Sudoeste do Estado de Goiás entre as latitudes $17^{\circ} 51^{\prime}$ e $18^{\circ} 21^{\prime} \mathrm{S}$ e as longitudes $52^{\circ} 43^{\prime}$ e $53^{\circ} 01^{\prime} \mathrm{W}$. Esta área abrange o Parque Nacional das Emas e boa parte da área agrícola que encontra em seu entorno. Região que se localiza na divisa dos estados de Mato Grosso e Mato Grosso do Sul, situado em um chapadão com relevo levemente ondulado, no Planalto Central Brasileiro, possuindo cerca de $75 \%$ a $80 \%$ do seu território com as fitofisionomias típicas de campos limpos e campos sujos, o restante da área é composto por veredas. No entorno no PNE é encontrado uma das maiores áreas de fronteira agrícola consolidadas no Brasil, e a Fig. 2 mostra claramente essa ocupação por grandes domínios de grãos que movimenta o crescimento do agronegócio no Brasil Pires (2007).

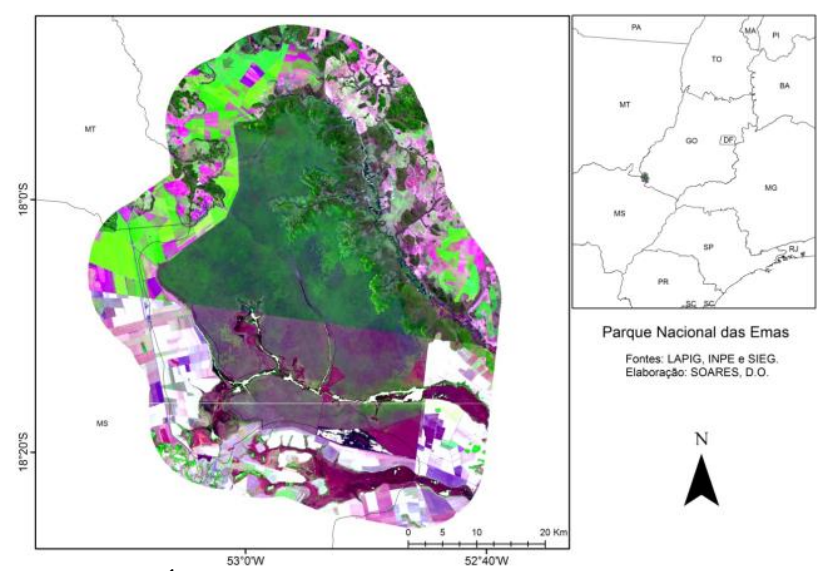

Figura 2: Área de Estudo - Parque Nacional das Emas e sua localização no extremo sudoeste goiano e divisa com estados do Mato Grosso e Mato Grosso do Sul. Ao redor da divisa do PNE é possível visualizar as marcas de uso do solo pela agricultura. Fonte: Autor

O segundo passo do trabalho foi a escolha das órbitas pontos, das cenas do satélite Landsat 5 TM. Selecionadas duas cenas do satélite referido: 224/72 e 224/73 buscou-se delimitar a região do Parque Nacional das Emas. Ao fazer o recorte da área de estudo, foi incluído também um buffer de $10 \mathrm{~km}$, ao redor deste parque. Essa região se encontra no extremo sudoeste do Estado de Goiás e é uma zona que vem sofrendo pressões antrópicas, impostas pelo avanço da fronteira agrícola Vidolin et al (2004).

As imagens foram adquiridas em 20 de agosto de 2011 para a cena 224/72 e 26 de agosto de 2011 para a cena $224 / 73$, por ser predominantemente um mês de seca para a região, todas as imagens adquiridas, tiveram pouca ou quase nada de cobertura de nuvens. A aquisição foi realizada por meio de catálogo digital do Instituto Nacional de Pesquisas Espaciais (INPE). E ainda, através de convênio inter-institucional entre o Laboratório de Processamento de Imagens e Geoprocessamento LAPIG/UFG e Ministério do Meio Ambiente - MMA, adquiriu-se imagens de satélite Rapid Eye, também do ano de 2011, com o mínimo possível de cobertura de nuvens. Essa data foi escolhida em função da disponibilidade da imagem Rapid Eye pelo convênio. 
Além das bases vetoriais provenientes das plataformas LAPIG e Sistema Estadual de Geoinformação de Goiás SIEG. Ao todo, o trabalho envolveu 2 imagens de satélite de média resolução espacial Landsat 5 TM (30 metros) para testes de segmentação e classificações e 34 imagens de satélite de alta resolução espacial da série Rapid Eye (5 metros), para a validação.

O terceiro passo foi o registro das imagens Landsat 5 TM. A realização do registro utilizou como referência, as imagens GLS (Global Land Survey), que já são registradas, sendo estas, disponibilizadas juntamente ao catálogo digital do Instituto Nacional de Pesquisas Espaciais (INPE). Escolheu-se para este trabalho o software ArcGis 10.1, com distribuição de 50 pontos, gerando o erro médio de 0,5 pixel. As imagens Rapid Eye foram disponibilizadas pelo Ministério de Meio Ambiente - MMA no nível registrado e ortorretificado de processamento. Foi feito o mosaico das imagens Landsat 5 TM e Rapid Eye, para fazer o recorte do Parque Nacional das Emas e o seu buffer de $10 \mathrm{~km}$, conforme Lei Federal $n^{\circ} 9.985$ regulamentada em 2000, que define uma zona de amortecimento em torno das Unidades de Conservação, em que as atividades antrópicas têm normas e restrições específicas, para minimizar os impactos negativos sobre a mesma.

Realizou-se um teste com a segmentação/classificação das imagens, conforme figura 3. Nesse teste adotou-se a segmentação das imagens pelo software Envi 5.0. Com a ferramenta Feature extractionexample based foram adotados os seguintes parâmetros: segmentação pelo algoritmo Edge com nível de escala 50, merge pelo algoritmo Full Lambda Schedule com nível 70 e textura tipo kernel de tamanho 3. Esses parâmetros foram escolhidos porque ao gerarem a segmentação/classificação, as bordas foram mais precisas e o tempo médio de processamento dessas imagens era de no máximo 15 minutos. Essa rapidez mostrou-se importante porque nos casos em que ao iniciar a inspeção visual, percebendo-se a necessidade de ajustar o nível de merge, o procedimento era mais facilmente realizado e/ou refeito, tornando o trabalho mais eficaz.

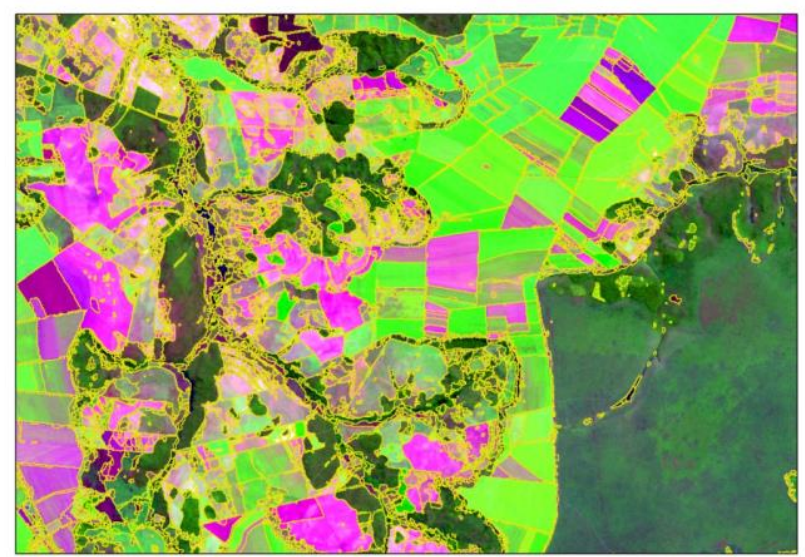

Figura 3: Segmentação de Imagem Landsat 5 no Envi 5.0. Fonte: Autor

\section{RESULTADOS E DISCUSSÕES}

$\mathrm{Na}$ classificação não-supervisionada foram coletadas as 5 classes que o algoritmo do sistema disponibiliza nesta metodologia e nomeadas conforme o mesmo padrão de classes como na classificação supervisionada. As classes utilizadas da classificação supervisionada foram 5 e baseadas nos seguintes usos: Agricultura, Vegetação, Pastagem, Veredas e Água. Essas classes foram definidas, levando em conta o histórico de uso do solo da região. O trabalho de inspeção/validação de imagens da área de estudo para avaliar o uso do solo foi feito através das imagens de alta resolução Rapid Eye. A inspeção visual nas imagens Rapid Eye foi realizada depois de já estarem prontas as classificações/segmentações das cenas Landsat 5 TM. Isto permitiu manter aproximada a resolução do trabalho final das diferentes imagens, dando aspecto de continuidade, apesar da diferença de resolução espacial das imagens.

Através dos processamentos obtiveram-se três mapas de cobertura e uso do solo referentes ao processo supervisionado, não supervisionado e de validação. Na tabela 1 temos a área total $\mathrm{em}^{\mathrm{km}^{2}}$ de todas as classes.

Tabela 1. Área das classes de uso e ocupação do solo do Parque Nacional das Emas e 10 km do seu entorno.

\begin{tabular}{lrrr}
\hline Classes & Não & Supervisionada & Validada \\
& Supervisionada & & \\
\hline Agricultura & 367,61 & 1241,68 & 1257,58 \\
Pastagem & 763,64 & 213,83 & 176,5 \\
Vegetação & 1055,26 & 1453,03 & 1545,12 \\
Veredas & 863,75 & 226,01 & 206,52 \\
Água & 138,2 & 64,92 & 14,62 \\
\hline
\end{tabular}

As duas classificações tanto supervisionada, quanto não supervisionada possuem suas importâncias em relação ao trabalho e a depender do critério estabelecido, bem como da escala usada. Mas em trabalhos com áreas de estudo onde o recorte é menor e os detalhes precisam ser maiores, além de poucas cenas, o reconhecimento das classes se torna mais acurado numa classificação supervisionada do que em uma não supervisionada Silva et al (2013). Baseando-se às taxas de amostras coletadas, bem como os índices gerados por $\mathrm{km}^{2}$ da classificação supervisionada, ser mais aproximado aos índices da validação, a classificação supervisionada foi mais eficiente na caracterização e identificação dos tipos de uso do solo no recorte escolhido (PNE), pois houve um melhor reconhecimento das áreas classificadas/segmentadas. Foi melhor também, por se tratar de recorte espacial de um parque, que compreende a uma área de 132642,07 hectares (ICMBio). Ela possui uma resposta de acurácia eficiente ao padrão de escala da área, ocasionando um erro menor em relação a essas 
amostras. Na figura 4, pode-se visualizar, a partir de mapa temático, o resultado da classificação não supervisionada com graduação de cores e suas classes.

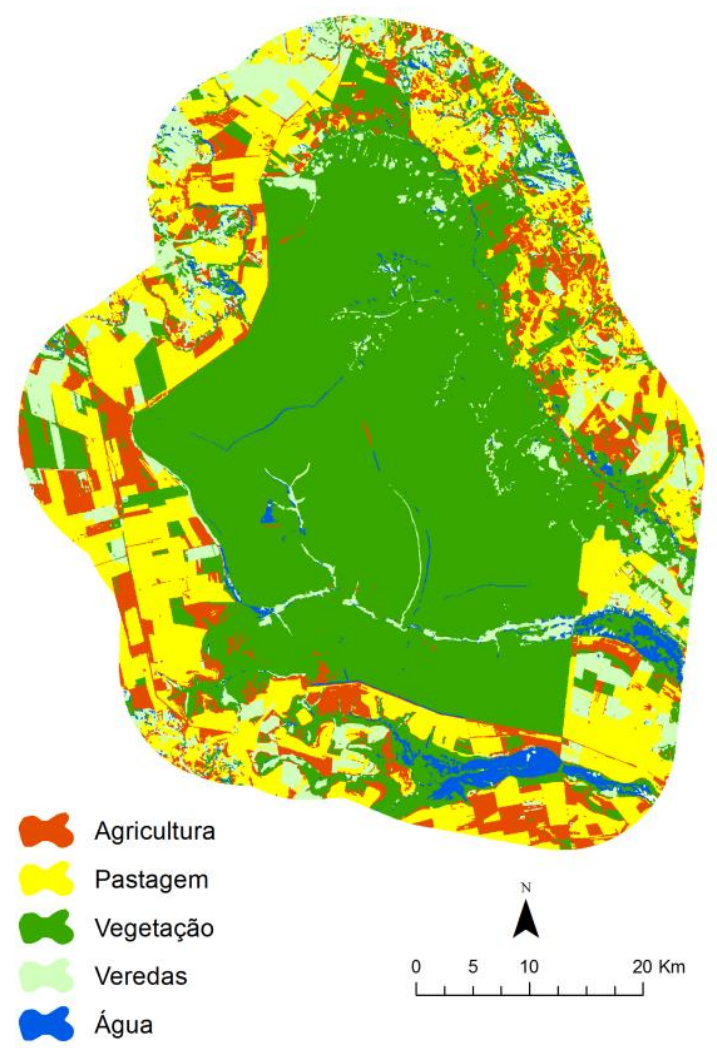

Figura 4: Classificação não supervisionada do Landsat 5 no Envi 5.0. com 5 classes de amostras.

Fonte: Autor

É possível perceber que o reconhecimento das classes em que cada pixel estava inseridos, não foram tão precisos, na classificação não supervisionada, gerando um erro de resposta quanto ao uso do solo, que poderá ser resolvido a partir de uma validação. Por se tratar de uma área pequena a média, com tal recorte espacial, seria inviável o uso da classificação não supervisionada. Já no caso da classificação supervisionada, essa propõe melhor resposta, como pode ser observado na Fig. 5.

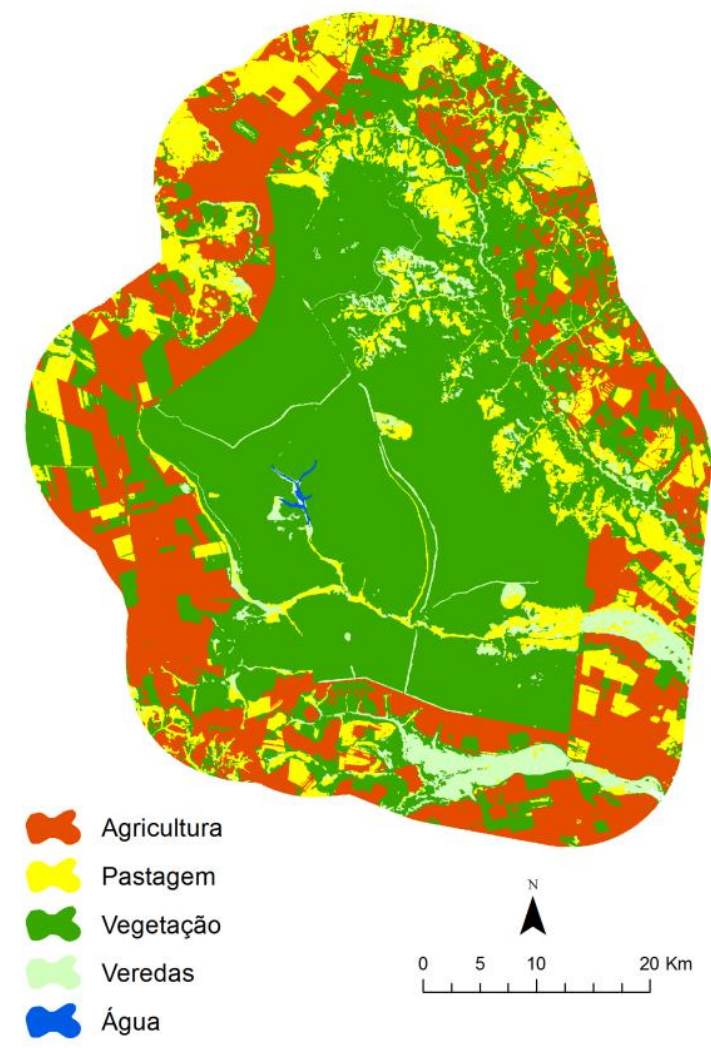

Figura 5: Classificação supervisionada do Landsat 5 no Envi 5.0. com 5 classes de amostras.

Fonte: Autor

A classificação supervisionada conseguiu estipular valores muito próximos e parecidos com a validação feita pela inspeção visual. É notável que a presença de agricultura dentro do Parque não é real, foi percebido a partir de análise das imagens de sensoriamento remoto, resquícios de pastagens, por se tratar de uma Unidade de Conservação, na validação será verificado se é pastagem ou não, fazendo uma inspeção visual minuciosa. A classificação não possui critério $100 \%$ de acerto e essas correções poderiam ser realizadas através da validação, que também não possui $100 \%$ de acerto. O importante é estipular um padrão mínimo de erro, para que o trabalho compense a investigação. Por isso, sua validação foi importante, para verificar com eficiência, as generalizações de reconhecimento de pixels feitas pelas classificações no processamento, para o uso do solo na região e obter um resultado satisfatório. Na Fig. 6, apresenta-se o mapa do Parque Nacional das Emas com as classes validadas pelas imagens de alta resolução Rapid Eye, mapa gerado a partir dos polígonos de segmentação das imagens e classificação visual. 


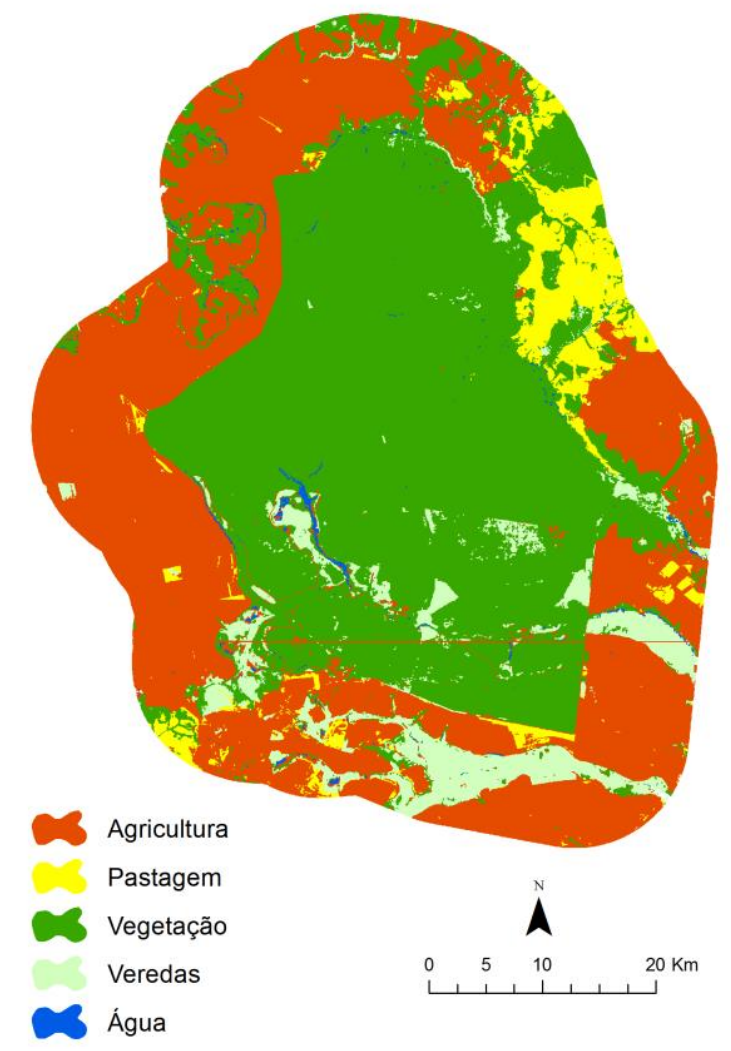

Figura 6: Resultado da Validação com imagens de alta resolução Rapid Eye.

Fonte: Autor

Foram observados a partir das classificações realizadas que a agricultura se distribui ao redor do PNE, principalmente nas partes Sul, Sudeste, Sudoeste, Oeste e Noroeste. Enquanto a pastagem ocorre de forma mais acentuada, onde o relevo é mais acidentado, na parte Nordeste do PNE.

As classificações para uso e cobertura do solo evidenciaram o processo de modernização da agricultura, que levou a uma pressão ao redor do parque, tornando o deslocamento das pastagens para solos mais baratos, menos férteis e de relevo acidentado Silva et al, (2013). Uma das características marcantes dessa troca de usos é a incorporação de áreas próximas aos cursos d'água às grandes áreas planas, sendo a homogeneidade visual do polígono o indício de que a pastagens foram substituídas pela agricultura. Na zona de amortecimento, conforme o que diz a lei 9.985, existe uma exigência de que seja estabelecida uma conservação dessa área de entorno de Unidades de Conservação. Isso se deve ao fato de que elas precisam desse amortecimento para minimizar danos decorrentes do aumento das pressões sobre os espaços protegidos. Entretanto, a zona de amortecimento do PNE está com uso de solo comprometido para agricultura ou pastagens. Essa situação mostra que pode ter havido desinteresse por parte de algum órgão de fiscalização ou autoridade competente, no que tange a exigência do cumprimento da legislação. Outro problema também para o parque se deve ao fato que essa pressão do uso do solo ao redor na sua zona de amortecimento, a partir de atividades antrópicas, pode ser responsável pelo agravamento de focos de queimadas anualmente e constantes nos períodos de seca, que por vezes, devastam toda a Unidade de Conservação e sua biodiversidade. Como não é mais possível reverter este cenário de uso atual e reconstituir para o natural as áreas perdidas de zona de amortecimento para as atividades antrópicas, o que ainda pode ser feito, são ações de monitoramento e fiscalizações rigorosas, bem como punição dos agentes responsáveis e sensibilização, para que as ações antrópicas não prejudiquem ainda mais a rica biodiversidade que o Parque Nacional das Emas representa.

\section{CONSIDERAÇÕES FINAIS}

Através desta análise buscamos melhorar a compreensão das aplicações e limitações da utilização do sistema de detecção por satélites para a realidade do PNE, bem como fazer comparação de métodos de classificação de imagens de sensoriamento remoto por segmentações, identificando assim o melhor padrão a ser utilizado naquele recorte espacial. Os resultados encontrados poderão subsidiar e contribuir com novas e futuras pesquisas no enfoque da detecção de mudança do uso e cobertura do solo além de fornecer informações às organizações governamentais e não governamentais que tratam a questão ambiental, para a interpretação destes produtos.

\section{AGRADECIMENTOS}

Este trabalho se insere entre as várias iniciativas do Laboratório de Processamento de Imagens e Geoprocessamento (LAPIG) voltadas ao monitoramento sistemático e gestão territorial do bioma Cerrado. Os autores agradecem ao Instituto Nacional de Pesquisas Espaciais (INPE) pela disponibilização das imagens ao Conselho Nacional de Desenvolvimento Científico e Tecnológico (CNPq) e à Coordenação de Aperfeiçoamento de Pessoal de Nível Superior (CAPES) pelas bolsas concedidas (Iniciação Científica). Suporte financeiro para esta pesquisa também foi obtido junto ao projeto: Políticas para o Cerrado e Monitoramento do Bioma - Iniciativa Cerrado Sustentável - MMA: TerraClass Cerrado.

\section{REFERÊNCIAS BIBLIOGRÁFICAS}

BELLARBY, Jessica; FOEREID, Bente; HASTINGS, Astley. Cool farming: Climate impacts of agriculture and mitigation potential. Geenpeace.org, 2008. 43 p.

DELLA Giustina, CARLOS CHRISTIAN; DE ANDRADE Franco, José Luiz. O Uso Insustentável dos Recursos Naturais no Estado de Goiás: Efeitos da agricultura na conservação do bioma Cerrado. Fronteiras-Journal of Social, Technological and Environmental Science, v. 3, n. 1, p. 55 a 65, 2014. 
FRANÇA, Helena; RAMOS NETO, Mário Barroso; SETZER, Alberto. O fogo no Parque Nacional das Emas. MMA, Ministério do Meio Ambiente, 2007.

FRANCO, Íria Oliveira; ASSUNÇÃO, Hildeu Ferreira da. Usos do solo no advento do agronegócio da canade-açúcar no sudoeste de Goiás: estudo de caso do município de Jataí. Ciência e Cultura, v. 63, n. 3, p. 33-36, 2011.

GLATZLE, Albrecht. Questioning key conclusions of FAO publications 'Livestock's Long Shadow'(2006) appearing again in 'Tackling Climate Change Through Livestock'(2013). Pastoralism, v. 4, n. 1, p. 1-6, 2014.

ICMBio - Instituto Chico Mendes. Disponível em: < http://www.icmbio.gov.br/portal/biodiversidade/unida des-de-conservacao/biomas-

brasileiros/cerrado/unidades-de-conservacaocerrado/2093-parna-das-emas.html>. Acesso em: $13 / 04 / 2015$.

MACEDO, Marcia N. et al. Decoupling of deforestation and soy production in the southern Amazon during the late 2000s. Proceedings of the National Academy of Sciences, v. 109, n. 4, p. 1341-1346, 2012.

MMA. Lei ${ }^{\circ} 9985$ de 18 de julho de 2000. Disponível em:

<http://www.mma.gov.br/port/conama/legiabre.cfm?c odlegi=322>. Acesso em: 15/04/2015.

PIRES, Cristine. Desenvolvimento Barrado pela Infraestrutura (2007). Disponível em: <http://www. acendebrasil.com.br/archives/files/2007_07_30_Jornal $\% 20 \mathrm{do} \% 20 \mathrm{Com} \% \mathrm{C} 3 \%$ A9rcio.pdf $>$. Acesso em 19/04/15.

SILVA, Elaine Barbosa da; FERREIRA, Laerte Guimarães; ANJOS, Antonio Fernandes dos; MIZIARA, Fausto. A expansão da fronteira agrícola e a mudança na cobertura e uso da terra no centro-sul de Goiás, entre 1975 e 2010. Ateliê Geográfico, Goiânia, v. 7, n. 2, p. 116-138, 2013. Disponível em: <http://www.revistas.ufg.br/index.php/atelie/article/vi ew/15660/15102>. Acesso em: 10 maio 2015.

VIDOLIN, Gisley Paula; BRAGA, Fernanda Góss. Ocorrência e uso da área por carnívoros silvestres no Parque Estadual do Cerrado, Jaguariaíva, Paraná. Cadernos da Biodiversidade, v. 4, n. 2, p. 29-36, 2004. 